\title{
Experimental Investigation of a Passive Direct Methanol Fuel Cell
}

\author{
Sujith Mohan and S.O. Bade Shrestha*
}

Department of Mechanical and Aeronautical Engineering, Western Michigan University, Kalamazoo, Michigan, USA

\begin{abstract}
Direct methanol fuel cells (DMFC) are getting increasing attention as a possible power source for application in the field of power electronics where the energy requirements are relatively small. The major advantage of the DMFC is their high energy density in comparison to the conventional batteries. In this study, the performance of a passive direct methanol fuel cell was investigated under five different methanol concentrations. To further investigate various losses in the fuel cell, impedance spectroscopy was employed to measure ohmic, activation and mass transport losses for all concentrations. It was observed that the performance of the fuel cell improved while the concentration of methanol solutions was closer to its corresponding stoichiometric values. Similarly, the temperature of the fuel cell was found to be higher as methanol concentration increases.
\end{abstract}

Keywords: Methanol, DMFC, anode and cathode losses, ohmic and mass transport losses, power and current density, impedance spectroscopy.

\section{INTRODUCTION}

The recent quest to curb global warming and gain energy independence has created a considerable interest and research in using alternative, renewable and sustainable fuels for energy production. Fuel cells play a vital role to overcome the dependence of carbon based fuels. A fuel cell being a device that converts the chemical energy stored in a fuel directly into electrical energy and heat through electrochemical reaction has tremendous potential [1]. Fuel cells have been used as energy conversion devices due to their robust construction without any moving parts and more importantly the high efficiency of conversion. Most of the fuel cells, like alkaline fuel cells or proton exchange membrane fuel cells use hydrogen directly as fuel. However, the major problems associated with using hydrogen as fuel are the storage, handling and transportation [2].

Direct methanol fuel cell (DMFC) has generated extensive interest from the point of view of research and application due to its simplicity which does not require the use of reformers and humidifiers [3]. DMFC uses methanol directly as fuel. The main advantage of using methanol as a fuel is readily available at low cost liquid fuel. Methanol has also got higher energy density than hydrogen and it can be stored and transported easily through the existing infrastructure [4]. In this contribution the performance characteristics of a passive DMFC has been investigated. A passive DMFC without any pumps was used to circulate methanol and oxidant suppliers to feed air into the system. The absence of these accessories makes the passive DMFC a promising choice of power source in toys \& electronic devices such as mobile phones. One of the major problems associated with the DMFC is its lower practical open circuit voltage $(\mathrm{OCV})$ in comparison to the corresponding

*Address correspondence to this author at the Department of Mechanical and Aeronautical Engineering, Western Michigan University, Parkview Campus, Kalamazoo, MI, 49008, USA; Tel: 269276 3432; Fax: 269276 3421; E-mail: Bade.Shrestha@wmich.edu theoretical value. This may be attributed to the phenomenon of methanol cross over through the membrane from the anode to the cathode side which reduces the cathode potential and thereby the overall voltage of the cell [5]. The reaction mechanism for a DMFC is:

Anode reaction:

$\mathrm{CH}_{3} \mathrm{OH}+\mathrm{H}_{2} \mathrm{O} \rightarrow 6 \mathrm{H}^{+}+6 \mathrm{e}^{-}+\mathrm{CO}_{2}$

Cathode reaction:

$1.5 \mathrm{O}_{2}+6 \mathrm{H}^{+}+6 \mathrm{e}^{-} \rightarrow 3 \mathrm{H}_{2} \mathrm{O}$

Overall reaction:

$\mathrm{CH}_{3} \mathrm{OH}+1.5 \mathrm{O}_{2} \rightarrow 2 \mathrm{H}_{2} \mathrm{O}+\mathrm{CO}_{2}$

Therefore, every molecule of methanol provides 6 electrons that pass from the anode to the cathode via external circuit providing electric current. The reversible OCV for a DMFC is $1.21 \mathrm{~V}$ [4].

\section{EXPERIMENT ARRANGEMENTS}

Several researchers have previously carried out experiments to evaluate the performance of DMFC. Ge and Liu [6] experimentally studied the parameters that affect the minimum polarization and crossover on DMFC performance by changing cell temperature, methanol concentration, and flow rate. Guo-Bin Jung et al. [7] studied the effect of operating parameters on the DMFC performance. In their study, they investigated the membrane electrode assemblies with different operating conditions such as membrane thickness, cell temperature and methanol solution concentration. The effects of these parameters on methanol concentration and power density were studied. Their study revealed that the open circuit voltage is inversely proportional to methanol solution concentration and is proportional to membrane thickness and cell temperature. It was also seen that the methanol crossover decreased with the increase in membrane thickness but led to an increase in ohmic resistance. 
This experiment was conducted on a single cell passive DMFC. The test cell was manufactured by Heliocentris. The cell specifications are shown in Table $\mathbf{1}$ below.

Table 1. Specification of the DMFC

\begin{tabular}{|c|c|}
\hline No of Cells & 1 \\
\hline Active Cell Area & $4 \mathrm{~cm}^{2}$ \\
\hline Manufacturer & Heliocentris \\
\hline
\end{tabular}

The passive DMFC came with a built in reservoir. The access of methanol to reaction areas purely depends on methanol diffusion process. Voltage and current measurements were made using an Amrel test load station. Impedance measurements were recorded using the built in Frequency Response Analyzer (FRA). The temperature was monitored using a K-type thermocouple. The DMFC and the load with the built in FRA unit is shown in Fig. (1).

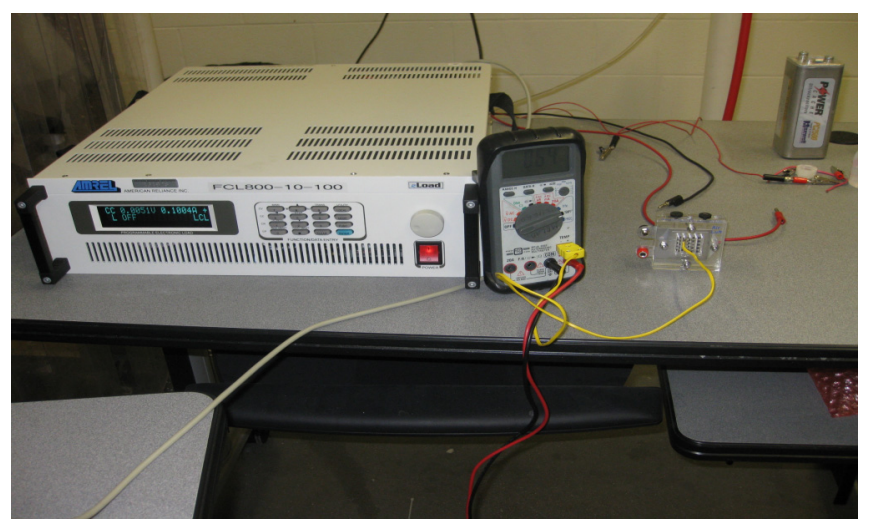

Fig. (1). Photograph of DMFC \& test station.

\section{Design of Experiment}

The experiment was conducted to determine the effect of fuel concentration on the output voltage and power density of the cell. The effect of methanol concentrations on the cell temperature was also investigated. The cell was tested under five different methanol concentrations $(0.25 \mathrm{M}, 0.5 \mathrm{M}, 1 \mathrm{M}$, $2 \mathrm{M}$, and $4 \mathrm{M})$. $\mathrm{M}$ represents the molar concentration of methanol in the solution and defined as the number of moles of substance in a liter of a solution. The experimental order was determined using statistical software called Minitab. A total of 140 runs were conducted to eliminate the possibility of testing error. All the experiments were conducted at atmospheric temperature and pressure if otherwise mentioned explicitly.

\section{RESULTS AND DISCUSSION}

The effects of five different methanol concentrations on the voltage-current (VI) characteristics of the fuel cell are presented in Fig. (2). As evident from the figure, there is a considerable increase in the output voltage when the methanol concentration was increased. The highest voltage was observed at two molar (2M) concentration as shown in Fig. (2). However, further increase in molar concentration produced the lower potential.

The average voltage for $2 \mathrm{M}$ concentration was about $45 \%$ higher than the average voltage for $0.25 \mathrm{M}$ or $4 \mathrm{M}$ concentration. However, the average voltage for $2 \mathrm{M}$ concentration was only $8 \%$ higher than the average voltage of $1 \mathrm{M}$ concentration. It means the cell performance continues to increase only up to a certain level of methanol concentration after which the performance of the cell begins to drop since the methanol crossover from the anode to cathode begins to affect considerably. The cell voltage began to fall substantially when the cell was operating at $4 \mathrm{M}$ methanol concentration solution. At stoichiometric condition, 1 mole of methanol requires 1 mole of water to produce 3 moles of hydrogen and 1 mole of carbon dioxide (Equation 1). Therefore, in terms of mass, 32.04 grams of methanol requires 18 grams of water, resulting the stoichiometric ratio of methanol to water as $32.04: 18$ which is 1.78 . While higher (or lower) concentration of methanol is used in the solution, there is insufficient (or excess) amount of water to combine with the entire methanol for production

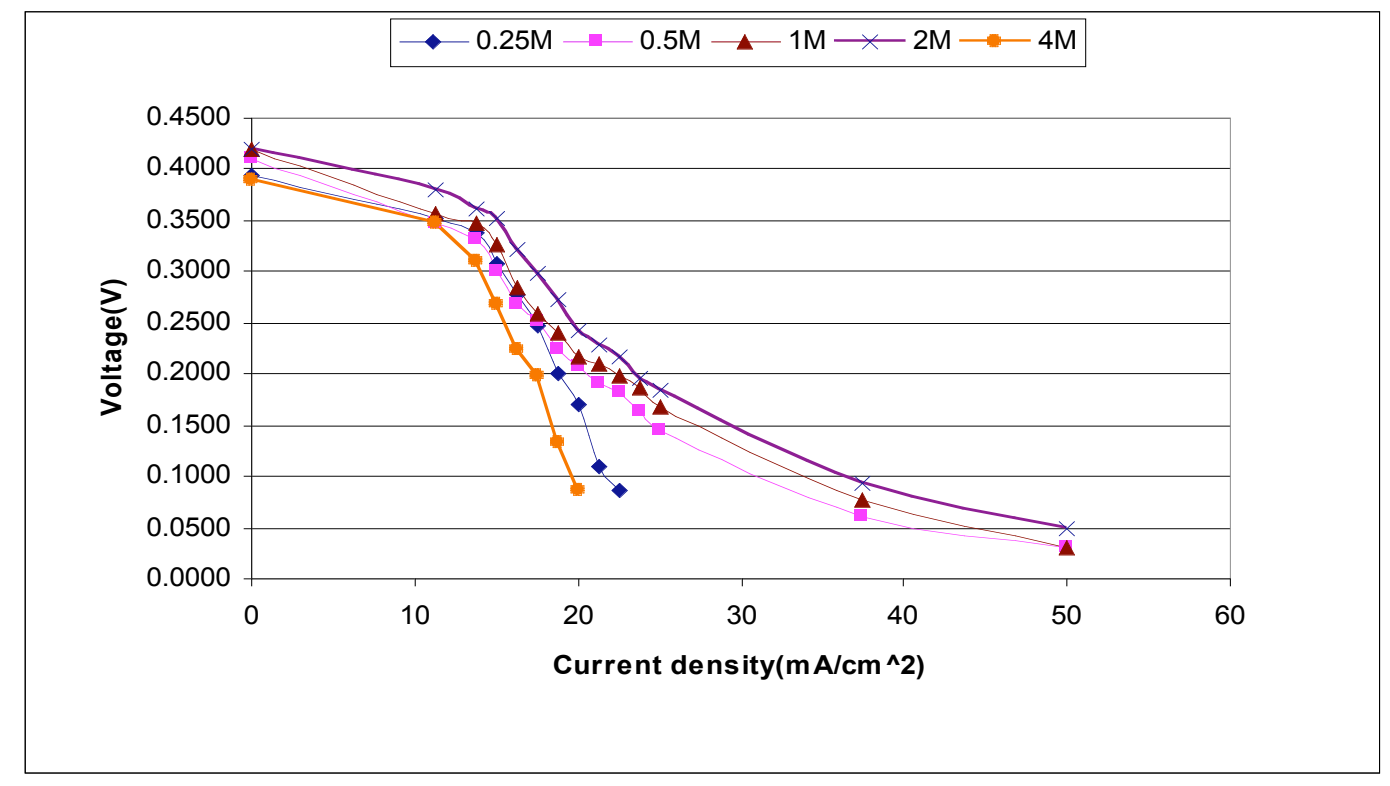

Fig. (2). VI curve showing effect of methanol concentrations. 


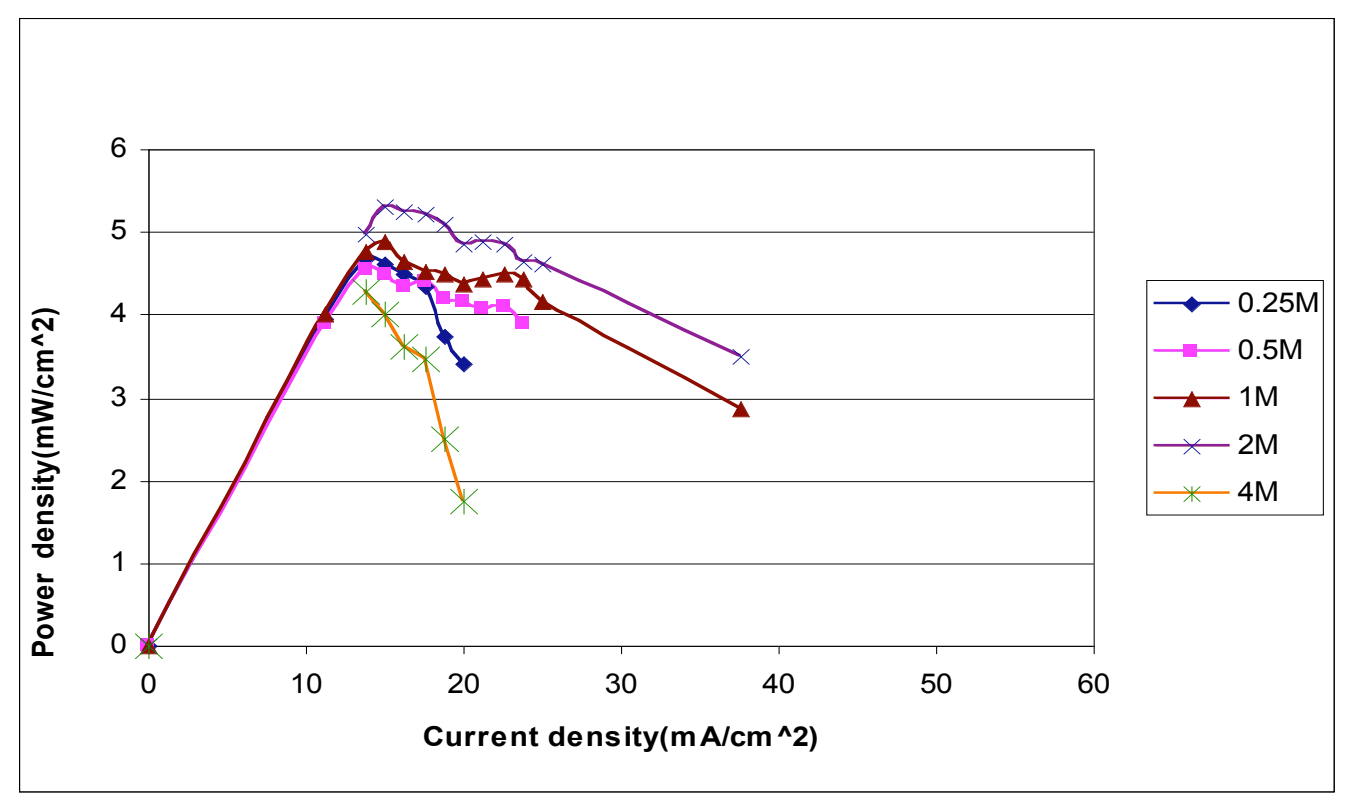

Fig. (3). Power density curves showing the effect of methanol concentration.

of hydrogen. Thus, the performance of the test cell was resulted lower as the molar concentrations were set away from the stoichiometric value as seen in the trends of the polarization curves in Fig. (2).

In Fig. (3), the effects of methanol concentrations on power density are presented. It shows that at low current densities, the power outputs were similar, though a little higher power density was obtained with the low methanol concentration solution. However, the performance of the DMFC was found better at higher current densities with a higher methanol concentration. It might be the result of relatively high temperature reached and increased molar content that enhanced electrochemical kinetics in comparison to the low or high molar concentration solutions.

\section{Effect of Concentration on Fuel Cell Temperature}

Fig. (4) illustrates the effect of concentration and temperature on the average cell output voltage. It is evident from the figure that the cell operating temperature increases with increase in concentration of methanol in the solutions. The average cell operating temperature under $2 \mathrm{M}$ methanol concentration solutions was found about $10 \%$ higher than the average cell operating temperature under $0.25 \mathrm{M}$ methanol solution.

\section{Impedance Spectroscopy}

To further analyze the V-I curve of the fuel cell performance; a more sophisticated test is required to accurately differentiate between all the major sources of

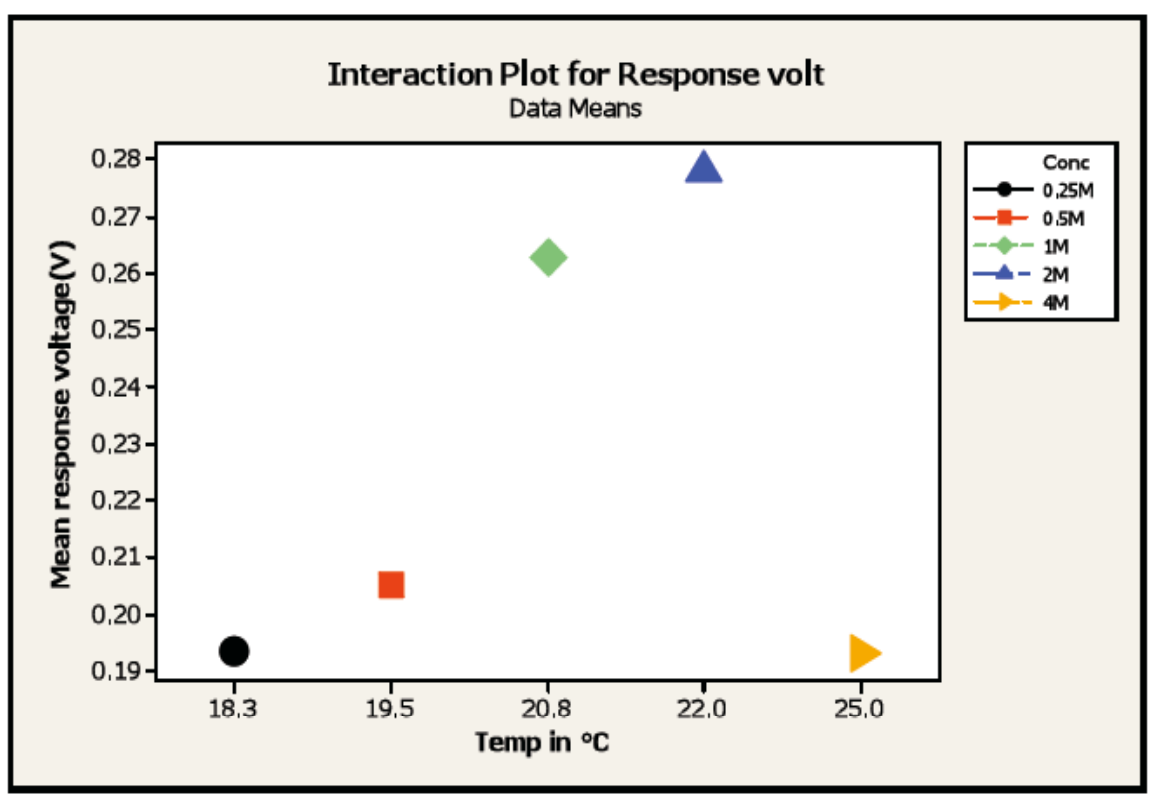

Fig. (4). Variation of mean response voltage with cell temperature at various methanol concentrations. 
losses in a fuel cell. One of the most widely used techniques for determining different losses in a fuel cell is electrochemical impedance spectroscopy [6]. Therefore, impedance spectroscopy technique was used to analyze various losses associated with the test cell employing an electronic load with a built in Frequency Response Analyzer (FRA) unit and Nyquist plots were generated to determine the various losses over a frequency range of $10 \mathrm{~Hz}$ to $15,000 \mathrm{~Hz}$. Nyquist plot furnishes a fair estimation of ohmic losses, cathode $\&$ anode activation losses and mass transport losses [8].

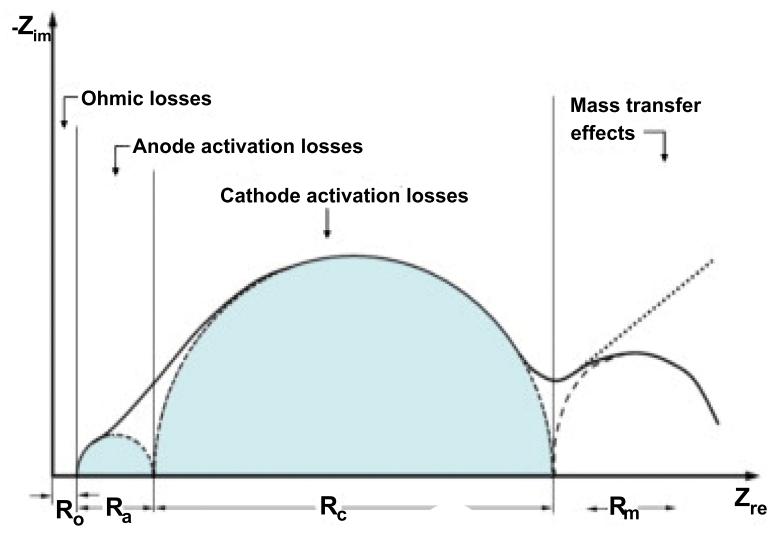

Fig. (5). Typical Nyquist Plot [8].

A typical Nyquist plot was shown in Fig. (5). $R_{\Omega}$ indicates ohmic resistance of the cell that is associated with the transportation of electron and ions through the system. $R_{a}$ represents the anode activation losses; $R_{c}$ represents the cathode activation losses. Activation losses are those associated with the huge initial loss. These losses correspond to the voltage lost to overcome the activation energy of the electrochemical reactions at the electrodes [9]. And $R_{m}$ represents the mass transport losses that are associated with the reactants and product species transportation within the cell [8].

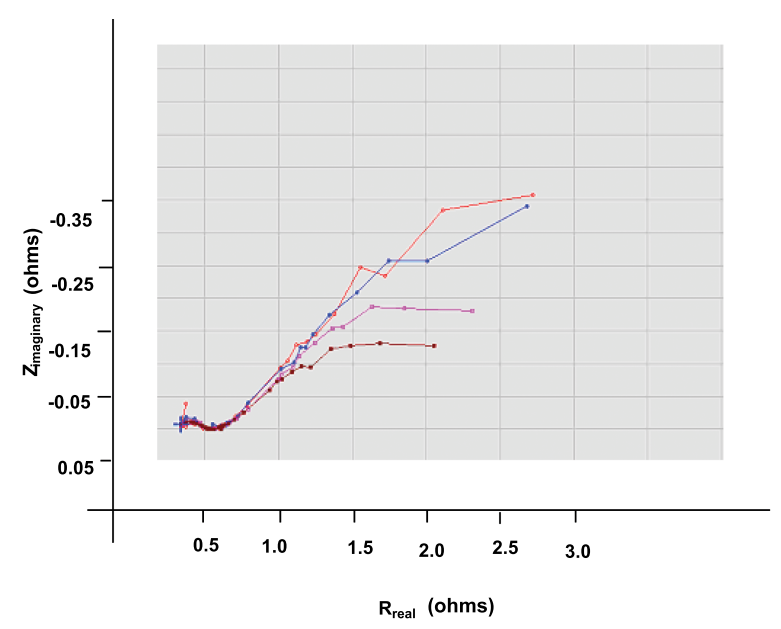

Fig. (6). Nyquist plot generated for $0.25 \mathrm{M}$ methanol concentration.

As a typical example, Fig. (6) illustrates Nyquist plot that was generated for $0.25 \mathrm{M}$ methanol concentration. The four curves represent impedance measurements at four different current values $(55 \mathrm{~mA}, 65 \mathrm{~mA}, 80 \mathrm{~mA} \& 100 \mathrm{~mA})$. The limiting current for this fuel cell was $120 \mathrm{~mA}$. Similar plots were generated for the test cell running at $0.5 \mathrm{M}, 1 \mathrm{M}, 2 \mathrm{M}$ and $4 \mathrm{M}$ methanol concentrations in the solutions. The resistances for different concentrations are presented in Table $\mathbf{2}$.

As it is expected, the mass transport losses were a magnitude higher than activation or ohmic losses as can be seen in Table 2 due to the significant fuel cross over. The activation losses were almost constant for various molar methanol concentrations employed, however the ohmic losses increased as the current increases, as expected. The mass transport losses were highest for 4M methanol concentration. The average mass transport losses for $4 \mathrm{M}$ methanol concentration solution were about $31 \%$ higher than the average mass transport losses for a $2 \mathrm{M}$ methanol concentration solution. There was a considerable increase in mass transport losses whenever the methanol solution deviated from the stoichiometric concentration of 1.78.

Table 2. Ohmic, Activation and Mass Transport Losses for Various Methanol Concentrations in Solutions

\begin{tabular}{|c|c|c|c|c|}
\hline $\begin{array}{c}\text { Methanol } \\
\text { Concentration }\end{array}$ & $\begin{array}{c}\text { Ohmic } \\
\text { Loss, } \\
\text { Ohms }\end{array}$ & $\begin{array}{l}\text { Activation } \\
\text { Loss, } \\
\text { Ohms }\end{array}$ & $\begin{array}{c}\text { Mass Transport } \\
\text { Loss, } \\
\text { Ohms }\end{array}$ & $\begin{array}{c}\text { Current } \\
\text { mA }\end{array}$ \\
\hline $0.25 \mathrm{M}$ & 0.343 & 0.20 & 1.734 & 55 \\
\hline $0.25 \mathrm{M}$ & 0.368 & 0.20 & 1.839 & 65 \\
\hline $0.25 \mathrm{M}$ & 0.370 & 0.20 & 2.118 & 80 \\
\hline $0.25 \mathrm{M}$ & 0.372 & 0.20 & 2.283 & 100 \\
\hline $0.5 \mathrm{M}$ & 0.400 & 0.20 & 1.734 & 55 \\
\hline $0.5 \mathrm{M}$ & 0.404 & 0.20 & 1.752 & 65 \\
\hline $0.5 \mathrm{M}$ & 0.408 & 0.20 & 2.076 & 80 \\
\hline $0.5 \mathrm{M}$ & 0.411 & 0.20 & 2.118 & 100 \\
\hline $1 \mathrm{M}$ & 0.375 & 0.20 & 1.337 & 55 \\
\hline $1 \mathrm{M}$ & 0.390 & 0.20 & 1.492 & 65 \\
\hline $1 \mathrm{M}$ & 0.392 & 0.20 & 1.692 & 80 \\
\hline $1 \mathrm{M}$ & 0.400 & 0.20 & 1.734 & 100 \\
\hline $2 \mathrm{M}$ & 0.282 & 0.19 & 1.213 & 55 \\
\hline $2 \mathrm{M}$ & 0.304 & 0.19 & 1.372 & 65 \\
\hline $2 \mathrm{M}$ & 0.334 & 0.19 & 1.573 & 80 \\
\hline $2 \mathrm{M}$ & 0.339 & 0.19 & 1.714 & 100 \\
\hline $4 \mathrm{M}$ & 0.376 & 0.20 & 1.804 & 55 \\
\hline $4 \mathrm{M}$ & 0.378 & 0.20 & 1.949 & 65 \\
\hline $4 \mathrm{M}$ & 0.380 & 0.20 & 2.115 & 80 \\
\hline $4 \mathrm{M}$ & 0.384 & 0.20 & 2.374 & 100 \\
\hline
\end{tabular}

The effect of concentration and temperature on the average mass transport losses is presented in Fig. (7). As it is evident in the figure, the mass transport losses were declining until for very rich concentration. It may be noted that the average cell operating temperature increases, as the methanol concentration is increased throughout. Generally, the increase in temperature with the increase in methanol 


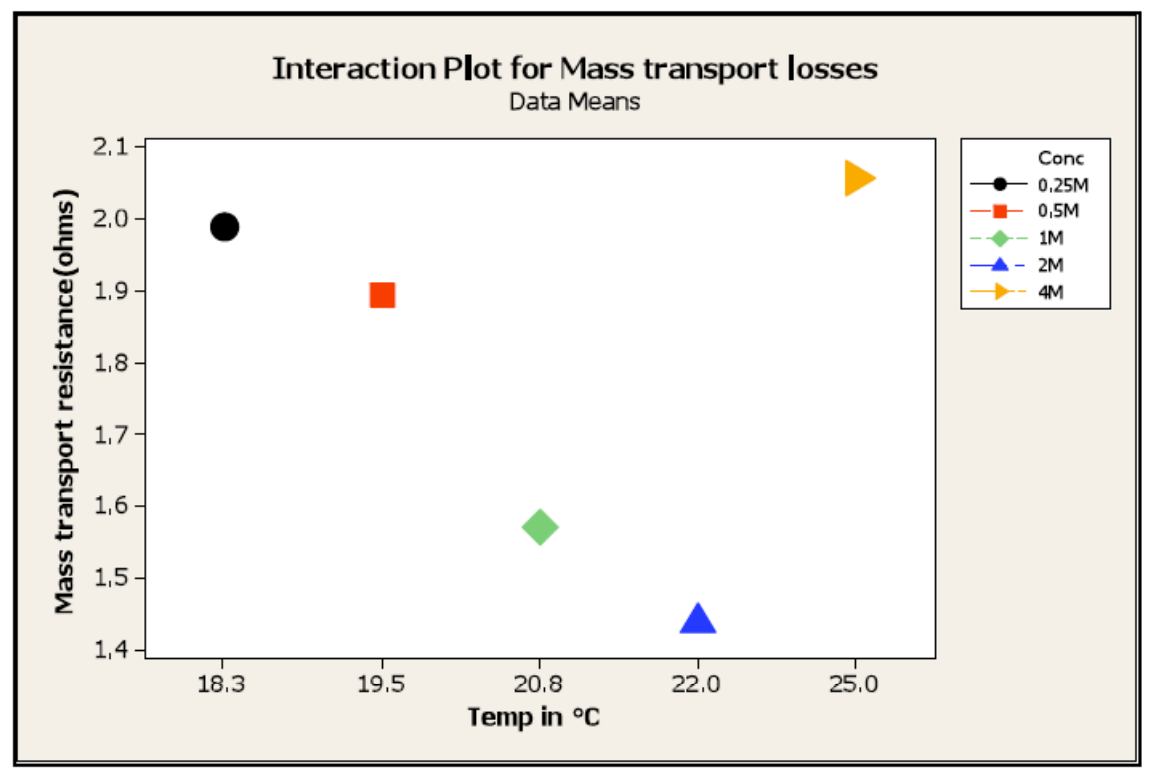

Fig. (7). Interaction plot for mass transport losses.

concentration assisted in improving the electrochemical kinetics of the reaction while reducing the mass transport losses providing the opportunity to operate the cell at higher current densities.

\section{CONCLUSION}

The performance of a passive direct methanol fuel cell was investigated under varying concentrations of methanol. The improved performance was observed whenever the molar concentrations of methanol in the solutions were closer to the corresponding stoichiometric values. The temperature of the cell increased with the increase in methanol concentration in the solution. Impedance spectroscopy revealed that the mass transport losses dominated in performance of the direct methanol fuel cell as expected. Generally, the mass transport losses were a magnitude higher than other losses.

\section{ACKNOWLEDGEMENTS}

The authors acknowledge for their assistance to Glenn Hall, Abraham Poot and Pete Thannhauser in fabrication of the experimental set up and data acquisition systems. The financial support of the Consumers Energy Foundation is also acknowledged.

\section{REFERENCES}

[1] Vielstich, W. Fuel Cells: Modern Processes for Electrochemical Production of Energy; Wiley \& Sons: New York, 1970.

[2] Zhigang, Q.I.; Arthur, K. Open circuit voltage and methanol crossover in DMFCs. J. Power Sources, 2002, 110, 177-185.

[3] Liu, J.G.; Zhao, T.S.; Chen, R.; Wong, C.W. The effect of methanol concentration on the performance of a passive DMFC. $J$. Electrochem. Commun., 2005, 7, 288-294.

[4] Larminie, J.; Dicks, A. Fuel Cell Systems Explained, Wiley \& Sons: New York, 2003.

[5] Seo, S.H.; Lee, C.S. Effect of operating parameters on the direct methanol fuel cell using air or oxygen as an oxidant gas. J. Energy Fuels, 2008, 22, 1212-1219.

[6] Ge, J.; Liu, H. Experimental studies of a direct methanol fuel cell. J. Power Sources., 2005, 142, 56-69.

[7] Jung, G-B.; Su, A.; Tu, C-H.; Weng, F-B. Effect of Parameters on the DMFC Performance. J. Fuel Cell Sci. Technol., 2005, 2, 81-85.

[8] O'Hayre, R.; Cha, W.S.; Colella, W.; Prinz, F.B. Fuel Cell Fundamentals; Wiley \& Sons: New York, 2005.

[9] Rayment, C.; Sherwin, S. Introduction to Fuel Cell Technology Department of Aerospace and Mechanical Engineering, University of Norte Dame: Norte Dame, 2003. 